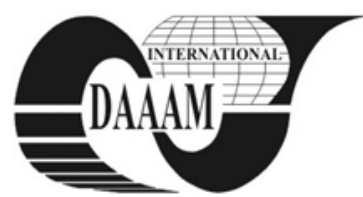

Annals of DAAAM for 2011 \& Proceedings of the 22nd International DAAAM Symposium, Volume 22, No. 1, ISSN 1726-9679 ISBN 978-3-901509-83-4, Editor B. Katalinic, Published by DAAAM International, Vienna, Austria, EU, 2011 Make Harmony between Technology and Nature, and Your Mind will Fly Free as a Bird

Annals \& Proceedings of DAAAM International 2011

\title{
COMPARISON OF LINEAR AND NONLINEAR MODEL PREDICTIVE CONTROL OF BENCHMARK DRUM BOILER
}

\author{
HORALEK, R[adek] \& HLAVA, J[aroslav]
}

\begin{abstract}
This paper deals with linear and nonlinear model predictive control (MPC) applied to a benchmark nonlinear boiler. The motivation for this research is the necessity to achieve tighter power plant control in the wide range load following operation. Since the boiler exhibits considerable nonlinearity, nonlinear MPC (NMPC) is the natural choice. On the other hand, linear MPC is much simpler to design and operate. For these reasons, three variants of MPC algorithm were designed (linear MPC, multiple MPC and NMPC) and compared in simulation in the terms of control performance versus complexity trade-off.
\end{abstract}

Key words: model predictive control, drum boiler, non-linear systems, power plant control

\section{INTRODUCTION}

A strong emphasis on energy efficient production and tight emission control is now imperative. This fact has an important impact also on the field of automatic control. Traditional approach based on PI/PID control is no more able to achieve the level of control performance that is dictated by contemporary requirements (Aurora et al., 2004) and new control methods are needed. Model predictive control (MPC) as the most widely applied advanced control method is the natural choice. Although MPC based on linear process model (linear MPC) has become standard control approach in many areas of industry during last two decades, practical applications of nonlinear model predictive control (NMPC) are still rare (Qin \& Badgwell, 2003). However, advances in optimization strategies now open the way for the on-line implementation of NMPC in new areas such as power plant control.

The paper uses a case study of a power plant boiler given in (Pellegrinetti \& Bentsman, 1996) as a control benchmark. Three variants of MPC algorithm are designed (linear MPC, multiple MPC and NMPC) and compared in simulation. Since the boiler exhibits considerable nonlinearities as was described in (Horalek \& Hlava, 2009), it is not surprising that simulation results will show the higher performance of NMPC in comparison with linear and multiple MPC.

\section{BENCHMARK BOILER MODEL}

The boiler under consideration is the drum boiler benchmark described in (Pellegrinetti \& Bentsman, 1996). The nonlinear control oriented model of this boiler is given by equations (1-8) (Pellegrinetti \& Bentsman, 1996), where $y_{l}$ is the measured drum pressure (psi), $y_{2}$ is measured oxygen level (\%), $y_{3}$ is the drum water level (in) and $y_{4}$ is the steam flow rate $(\mathrm{kg} / \mathrm{s}) ; x_{1}$ is the drum pressure state $\left(\mathrm{kg} / \mathrm{cm}^{2}\right), x_{2}$ is the excess oxygen level state $(\%), x_{3}$ is the system fluid density $\left(\mathrm{kg} / \mathrm{m}^{3}\right)$ and $x_{4}$ is the exogenous variable related to the load disturbance intensity. Manipulated variables $u_{1}, u_{2}, u_{3}$ are the fuel flow rate, the air flow rate and the feed water flow rate with normalized values between $(0-1), w_{d}$ is the deterministic part of the disturbance that defines the load level. For the numerical values of the coefficients of this model see (Pellegrinetti \& Bentsman, 1996).

$$
\begin{gathered}
\dot{x}_{1}(t)=c_{11} x_{4}(t) x_{1}^{9 / 8}(t)+c_{12} u_{1}\left(t-\tau_{1}\right)-c_{13} u_{3}\left(t-\tau_{3}\right)+c_{14} \\
\dot{x}_{2}(t)=-c_{21} x_{2}(t)+\frac{c_{22} u_{2}\left(t-\tau_{2}\right)-c_{22} u_{1}\left(t-\tau_{1}\right)-c_{24} u_{1}\left(t-\tau_{1}\right) x_{2}(t)}{c_{25} u_{2}\left(t-\tau_{2}\right)+c_{26} u_{1}\left(t-\tau_{1}\right)} \\
\dot{x}_{3}(t)=c_{31} x_{1}(t)-c_{32} x_{4}(t) x_{1}(t)+c_{3} u_{3}\left(t-\tau_{3}\right) \\
\dot{x}_{4}(t)=-c_{41} x_{4}(t)+c_{42} u_{1}\left(t-\tau_{1}\right)+c_{43}+w_{d} \\
y_{1}(t)=c_{51} x_{1}\left(t-\tau_{4}\right) \\
y_{2}(t)=c_{61} x_{2}\left(t-\tau_{5}\right) \\
+c_{70} x_{1}\left(t-\tau_{6}\right)+c_{71} x_{3}\left(t-\tau_{6}\right)+c_{72} x_{4}\left(t-\tau_{6}\right) x_{1}\left(t-\tau_{6}\right) \\
+\frac{\left[c_{75} x_{1}\left(t-\tau_{6}\right)+\tau_{76}\right]\left[1-\tau_{77} x_{3}\left(t-\tau_{6}\right)\right]}{x_{3}\left(t-\tau_{6}\right)\left[x_{1}\left(t-\tau_{6}\right)+c_{78}\right]} \\
y_{4}(t)=\left[c_{81} x_{4}\left(t-\tau_{7}\right)+c_{82}\right] x_{1}\left(t-\tau_{7}\right)
\end{gathered}
$$

The main control objectives are as follows. Steam pressure and drum water level must be kept at their setpoints despite load variations. The fuel/air ratio in the combustion chamber must respect safety, efficiency and ecological requirements.

Since variables $u_{2}$ (air flow rate), $x_{2}$ (excess oxygen level state) and $y_{2}$ (excess oxygen level) represent an independent system and output variable $y_{4}$ (steam flow) is considered as the uncontrolled output variable, we assume that the excess oxygen level is controlled by a ratio controller. Consequently the model can be simplified to a system with 2 inputs, 3 states and 2 outputs, given by (1), (3), (4), (5), (7).

\section{CONTROLLERS DESIGN}

Three MPC controllers were designed: linear MPC controller, multiple (linear) MPC controller and finally nonlinear MPC controller.

The nonlinear model was linearized analytically and discretized with sampling period $1 \mathrm{~s}$. The following operation point was used for linear MPC:

$$
\begin{aligned}
& x^{0}=\left[\begin{array}{llll}
22.5 & 2.5 & 621.17 & 0.6914
\end{array}\right]^{T} \\
& y^{0}=\left[\begin{array}{llll}
320 & 2.5 & 0.0 & 9.3053
\end{array}\right]^{T} \\
& u^{0}=\left[\begin{array}{lll}
0.3227 & 0.39503 & 0.37404
\end{array}\right]^{T}
\end{aligned}
$$

Multiple linear MPC controller consists of a set of linear controllers together switching rules. For this reason, very important part of controller design is to choose the proper set of the operating points. For doing this, the results published in (Horalek \& Hlava, 2009) were used and 7 linear controllers in 7 operating points given by computing steady state for different values of the state variable $x_{1}(7.5,12.5,22.5,32.5$ and $42.5 \mathrm{~kg} / \mathrm{cm}^{2}$ ) were designed. 
Both controllers were realized in Matlab/Simulink and Model Predictive Control Toolbox with following parameters: prediction horizon 500, control horizon 10, weights for output pressure and water level 1; 5, weights on increments of the control inputs $0.1 ; 0.1$ and quadratic optimization problem.

Although the principle of nonlinear MPC (NMPC) is the same as in the linear case, it is well known that design of NMPC is much more complicated mainly due to nonlinear and non-convex optimization that must be solved in every sampling period in very short time (Biegler, 2010). For doing this we used an open source software package for large-scale nonlinear optimization, called Ipopt (Wächter \& Biegler, 2006). Hence all simulations run in Simulink, optimization task is programmed in MSVisual C++ with using Ipopt and then it is called as an extern "MEX function".

The complete description of NMPC used for the simulations is out of scope of this paper and it can be found in (Horalek \& Imsland, 2011). The following parameters of the NMPC controller were used during the simulations: sampling period $0.5 \mathrm{~s}$, prediction horizon 300 (i.e. $150 \mathrm{~s}$ ), control horizon 300 , weights for output pressure and water level 1; 5, weights on increments of the control inputs are 0 .

\section{SIMULATION RESULTS}

Because of the contemporary requirements on operation in a wide operational range, the simulations with large changes of pressure setpoint were done and their results are in Fig. 1. Output pressure setpoint was increased from 320 psi to 440 psi. The biggest differences are in water level control where NMPC has faster response and no permanent deviation while pressure control performance is almost the same for all three controllers.
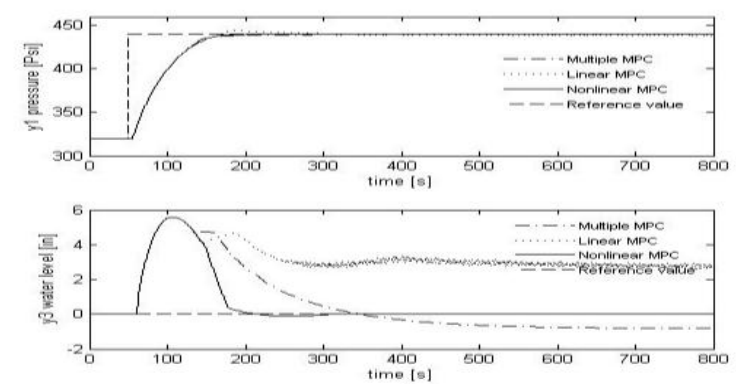

Fig. 1. Responses to setpoint change
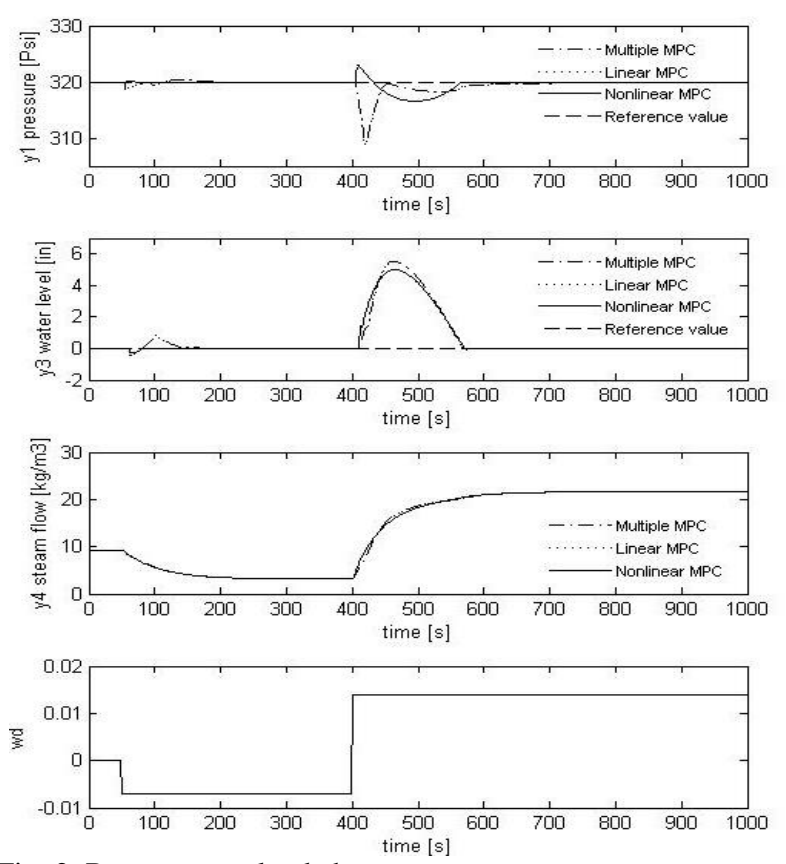

Fig. 2. Responses to load change
Further, control performance during load variations was tested (Fig. 2). $W_{d}$ is the deterministic part of the disturbance that defines the load level. Similarly as in (Pellegrinetti \& Bentsman, 1996; Liu et al., 2005; Fu et al., 2004) it was changed firstly from 0 to -0.07 and then from -0.07 to 0.014 . These values represent large load changes as it can be observed from corresponding steam flow changes in Fig. 2. In this simulation, NMPC controller shows better pressure control performance than linear and multiple MPC while all three controllers have almost the same results in water level control.

\section{CONCLUSION}

Three MPC controllers were designed for drum boiler model and their performance was tested in simulation. The performance of the linear MPC is the worst. The multiple MPC has better performance and still it is easy to implement. The NMPC has better water level control during changes of desired pressure, better pressure control during load changes and no permanent control deviation. Thus NMPC was found as suitable method when control requirements are strict and higher implementation and design costs are economically justifiable.

\section{ACKNOWLEDGEMENTS}

This research was supported by the Ministry of Education of the Czech Republic under contract No. 1M06059 "Advanced Technologies and Systems for Power Engineering”.

\section{REFERENCES}

Aurora, C.; Magni, L.; Scattolini, R.; Colombo, P.; Pretolani, F., \& Villa, G. (2004). Predictive control of thermal power plants. International Journal of Robust and Nonlinear Control, Vol. 14, No. 4, pp. 415-433, ISSN: 1099-1239

Biegler, L. T. (2010). Nonlinear Programming - Concepts, Algorithms, and Applications to Chemical Processes, SIAM, ISBN: 0898717020, Philadelphia

Fu, C.; Liu, J. \& Tan, W. (2004). Robust PI Design for a Benchmark Nonlinear Boiler. Proceedings of the 5th Asian Control Conference, July 2004, Melbourne, Australia, ISBN 0-7803-8873 -9, pp. 304-308

Horalek, R. \& Hlava, J. (2009). Piecewise affine approximation of nonlinear systems - a case study of a benchmark nonlinear boiler. Proceedings of the 8th WSEAS International Conference on System Science and Simulation in Engineering, Genova, Italy, October 2009, ISBN: 978960-474-131-1, Revetria R. (Ed.), pp. 273-277.

Horalek, R. \& Imsland, L. (2011). Nonlinear Model Predictive Control of a Benchmark Nonlinear Boiler. Accepted for XXIII International Symposium on Information, Communication and Automation Technologies, Sarajevo, October 27-29, 2011

Liu, J. Z.; Fu, C. F. \& Tan, W. (2005). Analysis and control of a benchmark boiler. Proceedings of the 2005 International Conference on Control and Automation, June 2005, Budapest, Hungary, ISBN: 0-7803-9137-3, pp. 374-378

Pellegrinetti, G. \& Bentsman, J. (1996). Nonlinear control oriented boiler modeling-a benchmark problem for controller design., IEEE Transactions on Control Systems Technology, Vol.4, No.1, pp. 57-64, ISSN: 1063-6536

Qin, S. J. \& Badgwell, T. A. (2003). A survey of industrial model predictive control technology. Control Engineering Practice, Vol. 11, No. 7, pp. 733-764, ISSN: 0967-0661

Wächter, A. \& Biegler, L. T. (2006). On the implementation of an interior-point filter line-search algorithm for large-scale nonlinear programming. Mathematical Programming, Vol. 106, No. 1, pp. 25-57, ISSN: 0025-5610 